University of Warwick institutional repository

This paper is made available online in accordance with

publisher policies. Please scroll down to view the document

itself. Please refer to the repository record for this item and our

policy information available from the repository home page for further information.

To see the final version of this paper please visit the publisher's website. Access to the published version may require a subscription.

Author(s: D. Chandler, G. Davidson, W.P. Grant, J. Greaves and G.M. Tatchell

Article Title: Microbial biopesticides for integrated crop management: an assessment of environmental and regulatory sustainability

Year of publication: 2008

Link to published version: http://dx.doi.org/ 10.1016/j.tifs.2007.12.009

Publisher statement: None 


\title{
Microbial Biopesticides for Integrated Crop Management: an assessment of environmental and regulatory sustainability
}

\author{
D. CHANDLER ${ }^{1}$, G. DAVIDSON ${ }^{1}$, W. P. GRANT ${ }^{2}$, J. GREAVES ${ }^{2}$, G.M. TATCHELL ${ }^{3}$ \\ ${ }^{1}$ Warwick HRI, University of Warwick, Wellesbourne, Warwick, UK CV35 9EF (Tel. +44 \\ (0) 2476575041; e-mail dave.chandler@warwick.ac.uk \\ 2 Department of Politics and International Studies, University of Warwick, Coventry CV4 \\ 7AL, UK (Tel. +44 (0) 2476523720; e-mail w.p.grant@warwick.ac.uk \\ ${ }^{3}$ Department of Biological Sciences, University of Warwick, Coventry CV4 7AL, UK (Tel \\ +44 (0) 1935 812514); e mail m.tatchell@warwick.ac.uk
}

\section{Introduction}

Herbivorous insects and mites, plant diseases and weeds are major impediments to the production of food crops. Farmers and growers are reliant on chemical pesticides for pest management, but the use of these agents is becoming more difficult due to the evolution of resistance in pest populations and product withdrawals, both of which are reducing the availability of effective compounds. There are also an increasing number of new threats from non-indigenous (i.e. invasive) pest species (Pimentel et al., 2005). At the same time, farmers and growers are trying to reduce the amounts of conventional chemical pesticides used, in response to demands from retailers. There is a requirement, therefore, to develop environmentally sustainable systems for controlling pests that are less reliant on chemical pesticides as the primary management tool. For most farmers, in order to maintain profitability, this must be done without sacrificing crop quality and productivity. The best way is through Integrated Pest Management (IPM) and Integrated Crop Management (ICM), which combine a range of complementary methods to reduce a pest population below its economic injury level while minimising impacts on other components of the agro-ecosystem, 
thus taking into account the needs of producers, wider society and the environment (Kogan, 1998). Chemical pesticides are not ruled out. Indeed, there is a new generation of chemical products with very good environmental and human safety characteristics. However, in ICM they are treated less as a blanket solution to crop protection and more as a precious resource, to be used selectively in ways that complement other methods and reduce the chances of resistance occurring. ICM assumes a broad palette of available control methods. Other ICM compatible methods include biological, cultural and physical controls, host plant resistance, and decision support tools. Yet, despite a wealth of evidence showing that they can be valuable components of ICM (Dent, 2000), there are relatively few biopesticides (i.e. mass produced biological agents for inundative pest control) on the market in the UK. This is particularly the case for microbial control agents (MCAs). We contend that a failings in the regulatory process has created a barrier to getting more products on the market, caused in part by failure to apply ecological theory to the environmental risk evaluation of products set within an overall regulatory framework that encourages innovation. This paper reviews some of the ecological and environmental issues concerning biopesticides, the possible failures in the regulatory process and examples of possible ways forward for the future use of biopesticides $^{1}$.

\section{Microbial Biopesticides in Integrated Crop Management}

Biopesticides are mass-produced, biologically based agents used for the control of plant pests. They can be divided into three sub categories (Copping \& Menn, 2000): (1) living organisms (primarily predatory insects, parasitoids, nematodes or micro-organisms); (2) naturally occurring substances, such as plant extracts or insect pheromones; and (3), as

\footnotetext{
${ }^{1}$ This paper arises from research conducted as part of the UK Research Councils' RELU Programme (award number RES-224-26-0048). RELU is funded jointly by the Economic and Social Research Council, the Biotechnology and Biological Sciences Research Council and the Natural Environment Research Council, with additional funding from the Department for Environment, Food and Rural Affairs and the Scottish Executive Environment and Rural Affairs Department.
} 
recognised in some countries, such as the USA, genetically modified plants that express introduced genes that confer protection against pests or diseases (so called plant incorporated products). Biopesticides are being used on increasing scales. For example, the management of invertebrate pests of protected edible crops in the UK and the Netherlands is now done mainly with natural enemies supplied by specialised companies (Van Lenteren, 2000).

This paper concerns microbial control agents (MCAs) aimed particularly at the control of invertebrate pests. MCAs are bacteria, protozoa, fungi or viruses that are natural enemies of phytophagous invertebrates, plant diseases or weeds and which are used for pest management (see Box 1). These micro-organisms are widespread in nature and contribute to the natural regulation of their hosts. They can also be used as tools for pest management and have a range of properties that make them desirable for ICM (Hajek, 2004). The micro-organisms selected for use as MCAs do not naturally infect vertebrates, and so are considered safe to humans, livestock and vertebrate wildlife. They produce little or no toxic residue, and development and registration costs are significantly lower than those of synthetic chemical pesticides (Hajek, 2004; D. Edgecomb, AgraQuest Inc., Sacramento USA, personal communication). They can be applied to crops using the same equipment used to apply chemical pesticides, and formulated in similar ways to pesticides to enhance their efficacy. However, it is their potential for self-perpetuating control that distinguishes them from chemical pesticides. Many microbial agents have high levels of specificity, making their use compatible with the deployment of other natural enemies. However, that host range can vary considerably depending on the type of control agent: thus, while entomopathogenic (i.e. insect pathogenic) baculoviruses are confined to a small number of closely related insect species or a single genus, some species of insect pathogenic fungi are able to infect hosts across a range of taxonomic orders (Tanada \& Kaya, 1993). 
Therapeutic microbial pest control agents are used in two main strategies. Firstly, the 'classical' approach is through the introduction of a host-specific, non-endemic natural enemy for the suppression of an alien (i.e. invasive) pest. One longstanding hypothesis is that invasive species become pests because, being in a new area, they have escaped their natural enemies (Torchin et al., 2003). The introduced control agent is expected to establish permanently and spread within its new environment. This does not require the mass production of control agents and has been implemented mainly through government programmes. Classical biological control has achieved successful pest control in a number of cases, although in general there is a lack of long term, quantitative and objective monitoring (i.e. embedded in ecological theory) of such programmes, which makes evaluation of the overall costs and benefits difficult (Thomas \& Reid, 2007). Secondly, augmentation biological control involves the application of natural enemies without the expectation of permanent establishment. It normally uses control agents supplied as products and has two forms: inoculative and inundative. Inoculative applications are based on pest control through the action of individuals of the released agent and their progeny (Hajek, 2004). The agent is expected to persist within the pest's environment although without permanent establishment. In contrast, inundative applications achieve rapid pest control by the mass application of individuals of the released agent only, with no expectation of control by their progeny. The efficacy of inundative control agents is dose dependent. Inundative control using microbial agents is akin to the use of chemical pesticides, which may explain why it is the most widely used form of microbial control. In reality, inoculation and inundation form a continuum, with the control agent persisting for varying periods depending on its biological characteristics, the availability of hosts, the ecological stability of the environment and the cropping system. For 
example, the use of some microbial agents to control plant pathogens relies on the establishment of the agent within the local environment of the pathogen (Whipps, 2001).

The focus of this paper is on microbial agents used according to the augmentation approach to biological control. There is little doubt that microbial products for augmentation biological control can make significant contributions to pest management as part of ICM (Dent, 2000, p223). Yet there are marked differences in the availability of products in different countries (see below). In this paper we explore opportunities to make product commercialisation more effective using (a) knowledge from microbial ecology to underpin environmental safety, and (b) insights from political science to provide innovation in the biopesticides regulatory system.

\section{Environmental safety considerations for microbial pest control agents used in augmentation biological control}

Accumulated experience by researchers and practitioners indicates that MCAs used in augmentation biological control can give effective pest control with minimal detectable negative impact on the environment (Vestergaard et al., 2003). But there is a lack of metaanalyses in the scientific literature of the long term impact of these agents. Providing such an analysis could be of considerable benefit to regulators of MCAs. Although detectable risks of MCAs are likely to be low, lack of evidence of negative effects does not mean that new microbial products should be exempt from safety testing, since different species and strains of a microbial species can vary significantly in host range, pathogenicity and other biological characteristics which can potentially affect environmental safety. Thus while there is a sense of urgency to the development of MCAs, a responsible approach is also required which puts

their use within the context of environmental sustainability (Bidochka et al., 1996). Effective 
methodologies need to be in place to determine the impact on non-target organisms. Such methodologies should be informed by ecological theory, as part of the development of a wider theoretical framework for biological control, founded on the advance of ecological information and understanding, including insights made in recent years in community ecology and invasion biology (Pearson \& Callaway, 2003; 2005). It should not be forgotten that early introductions of alien generalist vertebrate predators, such as cane toads in Australia, were done without proper consideration of the risks and with a poor understanding of ecological principles, resulting in unacceptable environmental consequences (Thomas \& Willis, 1998).

Impacts on non targets can be direct or indirect (e.g. competition between introduced and indigenous natural enemies). An MCA with a high level of host specificity means that unwanted direct effects on non-target organisms are likely to be rare. However, even hostspecific biological control agents can have impacts on non-target organisms through indirect effects (Pearson \& Callaway, 2005). The strength and nature of the impact will depend on the structure and dynamics of the community to which the MCA is introduced, the ability of the MCA to persist in the biotic and abiotic environment and, in the case of dose dependent MCAs, the size and density of its population. The ecological interactions determining the persistence and effects of the MCA are highly complex and include processes such as competition, predation / parasitism or synergism between the MCA and other natural enemies (Chandler et al., 1993; Roy \& Pell, 2000; Lockwood, 1993). Theoretical models indicate that the evolutionary relationships between microbial natural enemies and their hosts and / or habitats at a local scale is important for generating biological diversity in ecosystems (Dybdahl \& Storfer, 2003). If microbial natural enemies are adapted to their local 
environment, this could have profound implications for microbial pest control, including the efficacy of MCAs and effects on non targets.

Since classical control is based on the deliberate introduction of a non-indigenous natural enemy with the aim of permanent establishment, determination of host specificity is high on the agenda to ensure that agents released do not have negative effects on non-target organisms. There are well-established and proven systems for risk assessment and host range testing of classical control agents, led largely by researchers working on weed control (Andersen et al., 2005). People who use biocontrol and regulators are also bound by the FAO code of conduct on the import and release of biological control agents (FAO, 1996). Of course, host range evaluation is important for augmentative MCA products too, although procedures here have been criticised for concentrating on the physiological host range of agents (i.e. the potential host range as determined through laboratory bioassays) at the expense of studies of the ecological host range (i.e. the actual host range in the agroecosystem) (Jaronski et al., 2003).

Augmentative applications are not aimed at permanent establishment and the population of the released agent is expected to decline to background levels post application. Because the effects of these agents are dose dependent, any negative effects on non-target species should be temporary and last for as long as the agent persists. Anecdotal experience with agents such as entomopathogenic fungi used for augmentation biological control would appear to back this up, with no detectable detrimental environmental impact (Goettel et al., 2001). Such experience has an important bearing on the risk evaluation of new products, but - as outlined above - this is not to say that evaluation of new products is not required. To start with, inundative applications alter interaction in space and time between the microbial agent, 
its hosts and the environment (Jackson, 2003). If MCAs become used more widely, then the amount of environmental perturbation might increase. MCA manufacturers are under commercial pressures to use inundative agents with a relatively wide host range which could impact on a larger number of non-target organisms in the environment. Potentially, there could be unintended effects, for example, on the diversity and function of other natural enemies (including other strains of the MCA naturally resident in the area), or on sub-specific groupings of the target host species that are associated with non-crop plants (Lockwood, 1993; Roy \& Pell, 2000; Pearson and Callaway, 2003; Miller et al., 2003). Moreover, variation in the biological properties of different strains means that unexpected effects from new agents cannot be ruled out. A priori, applications of control agents that are endemic to the area of release should not be expected to cause permanent disturbance. However, exactly which entities are classed as 'endemic' may be more complex than it seems at face value. For example, many fungal species classified on the basis of morphological criteria have been described as having worldwide distributions. However studies using molecular tools and species concepts based on evolutionary biology indicate that an entity classified as a single species on the basis of morphology may in reality consist of an assemblage of 'hidden' or ‘cryptic’ species with differing geographical or host ranges (Desprez-Loustau et al., 2007). For commercial reasons, proprietary MCAs may involve the use of non-endemic strains in the area of release which could have potential to impact on endemic strains or non-target organisms if they persist. Therefore providing fundamental data on diversity and biogeography of microbial natural enemies is a critical step in underpinning risk evaluation.

We believe there is a strong case for making better use of ecological theory to develop a knowledge-based framework for biological control that includes the environmental risk evaluation of MCAs. This should enable regulators and others to respond better to future 
political developments based in part around potential conflicts of interest between stakeholders. These are associated with rising concerns for the conservation of biodiversity and threats from invasive species, set against the requirement to maintain or increase agricultural production without excessive reliance on chemical pesticides (for a discussion on the impacts of these tensions on the development of biological control agents, see Briese (2005)). The development of MCAs has largely followed a chemical pesticide model that does not exploit fully the favourable biological properties of the agents, in particular the potential for self-sustaining control that results from varying degrees of persistence in the environment (Waage, 1997). To make best use of these biological properties is likely to mean that more resources will have to be devoted to considering the potential and actual environmental impacts of MCAs, and the demands of that will depend upon the types of products developed. There is commercial pressure from the manufacturing side to develop products, based on a single strain, that are broad spectrum in order to control a range of pests on different crop types and may not be endemic to the areas of application. In contrast, environmentalists want to see narrow spectrum products based on strains taken from the area of use (Waage, 2001). In seeking to reconcile these divergent demands, it is important not to lose sight of the overall context. In particular, experience indicates that the products in use today have minimal negative environmental impact, while the potential impacts on the environment need to be balanced against the requirement for effective pest management. At the same time the potential environmental impact of MCAs needs to be seen against the impact of conventional chemical pesticides. The bottom line is that we need to have systems of evaluation that: (a) prevent the approval of agents that cause harm; (b) do not inhibit unduly the development of commercial products; and (c) promote sustainable pest management. 


\section{Microbial biopesticides: why such a low take-up?}

Microbial biopesticides represent less than $1 \%$ of the global market for agrochemical crop production (Hajek, 2004, p. 331). Of that, ninety per cent of world sales are derived from commercial preparations based on just one entomopathogenic bacterium, Bacillus thuringiensis (Advisory Committee on Pesticides, 2004, p. 15). Data on microbial biopesticide agents from Agriculture and Agri-Food Canada (Kabaluk \& Gazdik, 2005) and the US Environmental Protection Agency (EPA) indicates that more than 200 products are being sold in the US, compared to only 60 comparable products in the EU. In the UK only 5 microbial products are currently being sold, compared to 10 in Germany, and 15 each in France and the Netherlands.

There are various reasons why take up of biopesticides has been higher in the US than elsewhere. EPA and the individual states register or license pesticides for use. It has a separate Biopesticides and Pollution Prevention Division (BPPD) which promotes the use of biopesticides as components of IPM programmes, and also co-ordinates the Pesticide Environmental Stewardship Program (PESP). This is a voluntary programme that forms partnerships with pesticide users in order to reduce the potential environmental and health risks associated with pesticide use and implement pollution prevention strategies. EPA also tests biopesticides for safety but not for efficacy (efficacy testing may result in higher costs for biological than chemical pesticides). An Interregional Research Project (IR-4 Project), meanwhile, has earmarked funds for biopesticide research and registrations and is leveraging such funds through cooperative research with public sector researchers and venture capital biotechnology companies. 
One explanation for low take-up of biopesticides as a proportion of the global market for crop protection agents is market failure. In other words, the market size is too small to provide economies of scale and encourage firms to enter. Given that biopesticides are niche products with very specific applications, the market size for any one product is small. The US has a large market with substantial climatic variations, also helping to explain the greater use of biologicals. In theory a single market operates within the EU, 'as a dual system where the Community evaluates active substances and Member States evaluate and authorise products containing them' (European Commission, 2001, p. 2). The Commission accepts that mutual recognition does not work effectively, and directive 91/414 which deals with such issues is under revision. Progress on mutual recognition could create a larger market for biopesticides and overcome some of the problems of economies of scale.

Market failure, therefore, has a part to play in any explanation. An alternative hypothesis, however, is that of regulatory failure (and, of course, regulatory reform could reduce market failure problems as the US example illustrates). Systems of regulation can have unintended consequences. Bureaucratic theory points to a tendency for mechanisms to replace goals, for processes to become more important than outcomes. There may be consideration of policy instruments in isolation from their wider effects, and rules may be applied too rigidly. Systematic problems may arise in regulation, therefore, and there are also specific problems concerning the regulation of biopesticides. The safety and efficacy of biopesticides are regulated in the UK by the Pesticides Safety Directorate (PSD) and their use is governed by both national and EU level arrangements. The regulatory system was developed according to a chemical pesticides model, and this may act as a barrier to biopesticide commercialisation (Advisory Committee on Pesticides, 2003). The questions posed in relation to biopesticides are often not relevant and, therefore, do not facilitate the efficient registration of biological 
alternatives. As Waage puts it: 'biopesticide development is locked into an inflexible and unimaginative chemical pesticide model. In this position, all of the shortcomings of biopesticides relative to chemicals emerge and none of the benefits' (Waage, 1997, p. 14). Waage goes on:

'It is not the industry alone, but the entire pesticide regulatory process which has not adapted itself to the new opportunities which biopesticides provide. In their emphasis on high efficacy standards typical of fast-acting potent chemical products, registration procedures make little allowance for new products whose effect is a combination of direct kill and the conservation of natural enemies’ (1997, p.16).

Consequently, there is a potential government failure as the entry costs to the market are raised by an onerous registration process designed for chemical pesticides (Grant, 2005).

\section{Regulatory innovation}

However, regulation need not necessarily be incipiently conservative, and if appropriately designed and directed, may be an effective catalyst for change - hence our focus on regulatory innovation. We adopt a broad definition of regulatory innovation as innovation in any aspect of the regulatory system or regulatory regime (Black, 2005), ${ }^{2}$ including the performance of regulatory functions, institutional structures and organizational processes that other authors focus on more narrowly (Sparrow 2000; Moran 2003). Regulatory agencies/organisations often have scope to innovate within existing legislation. However, other types of innovation may require changes in statute. Both are of importance but this paper is concerned mostly with the former.

\footnotetext{
${ }^{2}$ A regulatory regime is the set of interrelated goals which are engaged in joint problem solving to address a particular goal. Its boundaries are defined by the definition of the problem being addressed, and it has some continuity over time (Hood et al, 2001).
} 
The challenge is to develop a regulatory system able to balance the broadly defined costs and benefits of biopesticides compared with synthetic pesticides. Given that existing actors in the policy network are primarily orientated towards chemical solutions, how can change be brought about? Policy network theory, which has been particularly extensively used in the analysis of agricultural policy, suggests that networks are good at managing incremental change, but tend only to innovate in conditions of crisis or exogenous shock. For defenders of the status quo, 'a sectoral policy network which has a high degree of cohesion among its members is a very powerful political resource' (Daugbjerg, 1998, p. 79). What emerges has characteristics of an elite cartel where participants collude so as to preserve the existing parameters of the policy-making process (Grant, 2000, p. 51). The situation is complicated by the fact that the EU has the leading role in pesticides legislation. Its system of decision making and inbuilt 'checks and balances' does not promote rapid policy change or paradigm shifts. Using the insights provided by policy network theory along with the evidence of interviews, we can identify agents and processes that create the conditions under which regulatory innovation could occur. Specifically, we can investigate whether environmentally friendly scientific and technological innovations in pest control are coincident with innovative regulatory regimes which meet concerns about environmental and public safety without unnecessarily constraining developments that would help achieve sustainability goals for the rural economy.

There is, of course, a danger that attempts at innovation end in counterproductive outcomes. Much of the regulatory reform literature treats 'innovation as success'. Mohr, for example, saw innovation as 'the successful introduction into an applied situation of means or ends that are new to that situation' (eg: Mohr, 1969, p. 112). It is defined by the Cabinet Office, 
moreover, as 'new ideas that work' (Cabinet Office, 2003, para 2.1). Moran’s thesis, however, is that innovation has been a 'fiasco', arguing that the last 30 or so years in the UK have been an era of 'hyper-innovation', 'the frenetic selection of new institutional modes, and their equally frenetic replacement by alternatives’ (Moran, 2003, p. 26). Black puts forward the following view:

'Innovation, quite clearly, need not be successful, and moreover being in a constant state of innovation can itself be counterproductive: initiatives are not given the time to be properly implemented; costs are imposed through the constant need to change systems and processes to implement new policies, and no policy is around for long enough for its success or failure to be properly assessed' (Black, 2005, p. 14).

Furthermore, how and when 'success' or 'failure' is measured, and from whose perspective, are all moot points. Assessments of success or failure often depend on where you stand: in other words, all innovations will have winners and losers. Therefore, innovations are not necessarily successes or failures, but "who judges what is 'good', at what point in the innovation’s 'life cycle’, and against what criteria, inevitably remain critically open questions” (Black, 2005, p. 15).

\section{Regulatory innovation in the UK and the Netherlands}

As noted above, regulatory failure in relation to biopesticides arises in particular from the application of an inappropriate model derived from the regulation of synthetic chemical pesticides. This could be overcome by regulatory innovation by the agency concerned, responding to a variety of stimuli. Two member states of the EU have devised schemes to 
cope with the difficulties arising in relation to the registration of biopesticides: the United Kingdom and the Netherlands.

These schemes arose in different circumstances and have different histories and they seek to achieve their objectives in somewhat divergent ways. Nevertheless, they perform somewhat similar functions. These may be summarized as follows. First, they seek to reassure developers of new products that the regulator is receptive to products that are not synthetic pesticides. Second, they seek to facilitate the successful completion of the regulatory process by providing advice and assistance on its requirements. Third, they seek to reduce the cost of registration by setting fees at a lower level than is customary or subsidising them.

\section{The Genoeg scheme in the Netherlands}

Genoeg is the acronym for Gwasbeschermingsmiddelen van Natuurlikje Oorsprong Effictief Gebruiken, which translates as using plant protection products of natural origin more effectively (or, more colloquially, the effective use of natural pesticides). Genoeg is the older of the two schemes considered here, exploratory work having started in $2001{ }^{3}$

Its broad objectives have been to get more natural pesticides registered; to learn about lower risk profiles; and to apply the knowledge and experience gained in statements for registration purposes. The first phase of the scheme, Project Genoeg Toegelaten, ran from 2003 to 2005 and led to the registration of four natural pesticides for use in glasshouses: Dipper (Citrex / ascorbinezur); Trianum (Trichoderma harzianum); BotaniGard (Beauveria bassiana); and Preferal (Paecilomyces fumosoroseus). The second phase, Project Genoeg Breed, ran from

\footnotetext{
3 The following accounts draws on interviews conducted in the Netherlands in 2007 with representatives of the managing consultancy and the pesticides regulatory authority.
} 
2004 to 2007 and entailed the support of ten natural pesticides for all uses. It is anticipated that there will be funding for a third phase.

The project was initiated by the Greenhouse Horticulture section of the Dutch Organization for Agriculture and Horticulture (LTO Glastuinbouw) and the Product Board for Horticulture (Productschap Tuinbouw). However, it also drew on political and financial support from the Ministry of Agriculture, as well as the Product Board for the first phase. The project is managed by a consultancy called the Centre for Agriculture and Environment (CLM) which has extensive experience in sustainable agriculture. It was started to serve as an intermediary between farmers and environmentalists and has good links with all the stakeholders, including the organic farming sector, who meet together two or three times a year. This consensus and coalition building has been a key element in the success of the project.

The first phase of the project also involved the construction of an inventory of pesticides of natural origin. In particular this sought to distinguish between effective and ineffective pesticides. The inventory was principally aimed at researchers and policy-makers, but could also be of use to growers as well.

Registration fees and some extra studies for the four applications were co-financed to a level that was not allowed to exceed fifty per cent of registration cost (up to a maximum of $€ 100,000)$. The allocated budget has been under spent. Literature search for a registration was undertaken by the National Institute for Public Health and the Environment (RIVM). This body has expertise in technical questions about ecotoxicology. The regulatory body, the Board for the Authorisation of Pesticides (CTB), provided a help desk facility to assist 
applicants and established a biopesticides team made up of six staff members has been set up, each with a defined expertise or speciality, e.g., characterisation, residues.

The first phase sought to identify bottlenecks in the process, which included costs of development and registration; knowledge dossier requirements, especially the complexity of dossiers; and the availability of expertise to evaluate natural products. There has been a problem with companies dropping out during the process. For many applicants, the cost of registration remained a problem with $€ 400,000$ being identified as a typical cost for the whole process. The second phase of the project places greater emphasis than the first phase on the pre-application process. In particular more attention is paid to the selection of products and offering advice to the applicant. Because of the variability of the products, however, it is sometimes difficult to generalize the steps involved.

\section{The UK Biopesticides Scheme}

In the UK there was concern about the lack of alternative control options, especially biological control agents. The Better Regulation Executive in the Cabinet Office encouraged the regulatory authority, the Pesticides Safety Directorate (PSD), to think about ways in which the registration of biological agents could be facilitated. This led to the introduction of the Pilot Project in June 2003. Its aim was to increase the availability of biological pesticides in the UK by improving knowledge and raise awareness of PSD requirements and how to meet them. ${ }^{4}$

One important mechanism was the use of pre-submission meetings. These take place between staff from the applicant company and experts at PSD. A number of such meetings

\footnotetext{
${ }^{4}$ The following account draws on interviews with PSD staff and observation of meetings at PSD.
} 
were observed on a non-participant basis as part of our research. A typical meeting might last between three to four hours with different experts from PSD joining the meeting as required. The meetings enabled the identification of gaps in the application dossier and mutually helpful discussions of how these could be filled, for example through published data.

Reduced fees are charged for biological control agents: £22,500 for biopesticides; £13,000 for pheromones and £7,500 for taking either through European Food Safety Agency (EGSA) procedures. These fees were not increased in March 2007 when other fees went up. In comparison, the cost of core dossier evaluation, provisional approval and EFSA review for a synthetic was £175,000 from March 2007.

The scheme has had to face a number of challenges. It has involved PSD reaching out to non-traditional 'customers' who may be suspicious of the regulatory authority because they have no experience of working with them. Biopesticides are typically produced by small and medium-sized enterprises that do not have the regulatory affairs divisions found in bigger companies. One mechanism for contact has been through the trade association, the International Biocontrol Manufacturers Association (IBMA) with whom PSD has developed an effective working relationship, e.g., through a joint working group on efficacy issues. However, not all manufacturers are necessarily members of the IBMA. It has also been necessary to reassure companies that all data supplied to PSD will remain confidential.

It is also important to engage in a dialogue with potential applicants at an early stage of the process of product development. This can help them to plan the acquisition of the data they need for registration and also avoid the compilation of any material which would be superfluous. In particular, it is helpful to hold a pre-submission meeting before efficacy 
trials take place. To help to build relationships with companies, PSD has appointed a designated Biopesticides Champion within the regulatory body. They have also developed an informal internal network of staff with interest and expertise in biopesticides issues.

The fee structure and success rate is dependent on the quality of submissions made. PSD operates on a 'cost recovery' basis so it cannot subsidise lower fees for biologicals from elsewhere or from funds provided by government. The hope is that the pre-submission meetings will lead to higher quality submissions which need less work and take less time to process, thereby reducing the costs involved.

Prior to the introduction of the scheme, three active substances and four products were approved between 1985 and 1997. Three products were approved under the Pilot Scheme which was replaced by a Biopesticide Scheme launched on 1 April 2006. This covered four categories: semiochemicals; micro-organisms (bacteria, fungi, protozoa, virus); natural plant extracts; and other novel products considered on a case-by-case basis. In April 2007 five products were at various stages of evaluation, and several other companies were discussing possible applications with PSD.

\section{Comparison of the Netherlands and the UK}

The two schemes in the Netherlands and the UK are structured in somewhat different ways. For example, in the Netherlands companies receive a subsidy from public funds while in the UK the fees are lowered. However, both regulatory agencies face the challenge of cost recovery. In the Netherlands, the process was more of a 'bottom up' one with a coalition of agencies and other actors creating a new process. In the UK, the process was more 'top down', initiated by an intervention from the Better Regulation Executive in the Cabinet 
Office with the regulatory agency then reaching out to other actors and building relationships. This was probably more time consuming and difficult to implement than the Dutch approach, but the difference is explained by the fact that relevant networks already existed in the Netherlands, stimulated in part by the economic importance of the protected crops sector. In the UK there has been more of a challenge in terms of building networks and some parts of the jigsaw are incomplete - retailers, for example, are not generally well integrated into the network. In both cases a key lesson has been the importance of meetings with applicants at an early stage in the application process to identify areas of difficulty and possible solutions.

Regulatory innovation has successfully occurred in the sense that new processes have been put in place and these continue to be developed on the basis of experience. Outcomes are relatively modest, although favourable compared to the preceding period. It is here that alternative hypotheses in terms of market size have to be considered and also the attractiveness of products to growers in terms of their efficacy and the management costs involved in their successful use.

\section{Conclusions}

Better understanding of microbial control agents using new insights from community ecology, biogeography and invasion biology can assist a regulatory process which, at least in Britain and the Netherlands, is seeking actively to adjust to the need for more registrations of biopesticides to help meet sustainability objectives. Scientific advances can thus feed directly into the enhancement of the regulatory process and foster the process of regulatory innovation. Improved understanding of the ecology of MCAs will have a double pay-off of better systems of environmental risk evaluation and of more effective and sustainable microbial control. As put by Jackson (2003), referring to the bacterial pest control agent 
Serratia entomophila 'While there will always be the potential of unanticipated and or unrecognised side effects from the use of bacterial biopesticides, the likelihood will be diminished with a good understanding of the science behind their use’. Areas that need attention include the following:

- Better understanding of phylogeny of microbial natural enemies (Rehner \& Buckley, 2005).

- Understanding of the biogeography of microbial natural enemies - the factors that determine distributions of species and strains and influence gene flow (Bidochka \& Small, 2005).

- Improved understanding of the factors determining the persistence and spread of microbial natural enemies, including interaction with the biotic and abiotic environment and community assembly.

- Determination of background levels of microbial natural enemies in agricultural and natural ecosystems (Mensink \& Scheepmaker, 2007). This should include prevalence and diversity from gene to community level, biomass and ecosystem function.

- Better understanding of population dynamics including pathogen-host dynamics, and indirect effects on non target organisms.

As one of the solutions to finding alternatives to chemical pesticides, biopesticides are still hampered by their lack of profile relative to other alternatives which reflects the weakness of the supporting policy network. IBMA, the trade association, is relatively poorly resourced and is limited in the extent to which it can make an impact on the debate at the EU level. From a political science perspective, a key failing is lack of integration in the network as defined by Daugbjerg (1998, p.42) in terms of 'the form, quality and frequency of interaction within the network.' Underlying problems include the relative immaturity of the policy 
network; limited resources and capabilities; and a lack of trust between some actors such as regulators and some firms who have not used revised approval processes. The lack of resources can impact on the way in which issues are framed as there are insufficient opportunities to influence decision-makers. A recent report by the Committee for the Environment, Public Health and Food Safety of the European Parliament refers to alternatives to chemical pesticides that could be 'Organic farming, crop rotation, weeding or possible substitution/partial substitution of pesticides by GMOs’ (European Parliament, 2007, p.8) without mentioning biopesticides. Better understanding of their mode of action and effects, and of the regulatory issues that arise in their adoption, may help to raise their profile among public policy-makers and hence enable them to realise their contribution to sustainability.

\section{References}

Advisory Committee on Pesticides. (2004). Final report of the sub-group of the Advisory Committee on Pesticides on: Alternatives to conventional pest control techniques in the UK: A scoping study of the potential for their wider use.

Andersen, M. C., Ewald, M. \& Northcott, J. (2005). Risk analysis and management decisions for weed biological control agents: Ecological theory and modelling results. Biological Control, 35, 330 - 337.

Bidochka, M. J. \& Small, C. L. (2005). Phylogeography of Metarhizium, an insect pathogenic fungus. In F. E. Vega \& M. Blackwell (Eds.), Insect fungal associations: Ecology and Evolution. (pp. 28-50). Oxford UK: Oxford University Press.

Bidochka, M. J., Walsh, S. R. A., Ramos, M. E., St Leger, R. J., Silver, J. C. \& Roberts, D. W. (1996). Fate of biological control introductions: Monitoring an Australian fungal 
pathogen of grasshoppers in North America. Proceedings of the National Academy of Sciences of the USA, 93, $918-921$.

Black, J. (2005). What is regulatory innovation? In J. Black, M. Lodge \& M. Thatcher (Eds.), Regulatory innovation. (pp.1-15). Cheltenham UK: Edward Elgar.

Briese, D. T. (2005). Translating host-specificity test results into the real world: The need to harmonize the yin and yang of current testing procedures. Biological Control, 35, 208 $-214$.

Cabinet Office. (2003). Innovation in the public sector. London UK: HMSO.

Chandler, D., Heale, J. B. \& Gillespie, A. T. (1993). Competitive interaction between strains of Verticillium lecanii on two insect hosts. Annals of Applied Biology, 122, 435-440.

Copping, L.G. \& Menn, J. J. (2000). Biopesticides; a review of their action, applications and efficacy. Pest Management Science, 56, 651-676.

Copping, L. G. (2004). The Manual of Biocontrol Agents. British Crop Protection Council, Farnham UK, 752 pp.

Daugbjerg, C. (1998) Policy Networks Under Pressure (Aldershot: Ashgate)

Dent, D. (2000). Insect Pest Management. Wallingford UK: CABI Publishing.

Desprez-Loustau, M-L., Robin, C., Buee, M., Courtecuisse, R., Garbaye, J., Suffert, F., Sache, I. \& Rizzo, D. M. (2007). The fungal dimension of biological invasions.

Trends in Ecology and Evolution, 22, 472 - 480.

Dybdahl, M. F. \& Storfer, A. (2003). Parasite local adaptation: Red Queen vs. Suicide King. Trends in Ecology and Evolution, 18, 523 - 530.

European Parliament (2007) Committee on Environment, Public Health and Food Safety, Draft Report on Thematic Strategy on the Sustainable Use of Pesticides, 14 March. 
Food and Agriculture Organization of the United Nations (FAO). (1996). Code of conduct for the import and release of Exotic Biological Control Agents. International Standards for Phytosanitary Measures (ISPM) (Publication No. 3), FAO.

Goettel, M. S., Hajek, A. E., Siegel, J. P. \& Evans, H. C. (2001). Safety of fungal biocontrol agents. In T. M. Butt, C. W. Jackson, \& N. Magan (Eds.), Fungi as biocontrol agents: progress, problems and potential. (pp. 347-376). Wallingford UK: CABI Publishing.

Grant, W. (2000) Pressure Groups and British Politics. Basingstoke: Palgrave-Macmillan.

Grant, W. (2005). The challenges of interdisciplinary environmental research: the case of biopesticides. Paper presented at the Northeastern Political Science Association Conference, Philadelphia.

Hajek, A. (2004). Natural enemies; an introduction to biological control. Cambridge UK: Cambridge University Press.

Hawksworth, D. L., Kirk, P. M., Sutton, B. C. \& Pegler, D. N. (1995). (Ainsworth and Bisby's) Dictionary of the fungi (Eighth Edition). CAB International, Wallingford, UK, 616 pp.

Hood, C., Rothstein, H. \& Baldwin, R. (2001). The government of risk: Understanding risk regulatory regimes. Oxford UK: Oxford University Press.

Jackson, T. A. (2003). Environmental safety of inundative application of a naturally occurring biocontrol agent, Serratia entomophila. In H. M. T. Hokkanen \& A. E. Hajek (Eds.), Environmental impacts of microbial insecticides. (pp. 169 - 176). Dordrecht The Netherlands: Kluwer Academic Publishers.

Jaronski, S. T., Goettel, M. S. \& Lomer, C. J. (2003). Regulatory requirements for ecotoxicological assessments of microbial insecticides - how relevant are they? In H. M. T. Hokkanen \& A. E. Hajek (Eds.), Environmental impacts of microbial 
insecticides. (pp. 237 - 260). Dordrecht The Netherlands: Kluwer Academic Publishers.

Kabaluk, T. \& Gazdik, K. (2005). Directory of microbial pesticides for agricultural crops in OECD countries. Agriculture and Agri-Food Canada. http://www.agr.gc.ca/env/pdf/cat_e_pdf (last accessed 28/06/2007)

Kogan, M. (1998). Integrated Pest Management: Historical perspectives and contemporary developments. Annual Review of Entomology, 43, 243-70.

Lockwood, J. A. (1993). Environmental issues involved in biological control of rangeland grasshoppers (Orthoptera: Acrididae) with exotic agents. Environmental Entomology, 22, $503-518$.

Mensink, B. J. W. G. \& Scheepmaker, J. W. A. (2007). How to evaluate the environmental safety of microbial plant protection products: a proposal. Biocontrol Science and Technology, 17, 3 - 20.

Miller, N. J., Birley, A. J., Overall, A. D. J. \& Tatchell, G. M. (2003). Population genetic structure of the lettuce root aphid, Pemphigus bursarius (L.), in relation to geographic distance, gene flow and host plant usage. Heredity, 91, 217 - 223.

Mohr, L. (1969). Determinants of innovation in organizations. American Political Science Review, 75, 111-26.

Moran, M. (2003). The British regulatory state: High modernism and hyper-innovation. Oxford UK: Oxford University Press.

Pearson, D. E. \& Callaway, R. M. (2003). Indirect effects of host-specific biological control agents. Trends in Ecology and Evolution, 18, 456 - 461.

Pearson, D. E. \& Callaway, R. M (2005). Indirect nontarget effects of host-specific biological control agents: Implications for biological control. Biological Control, 35, $288-298$. 
Pimentel, D., Zuniga, R. \& Morrison, D. (2005). Update on the environmental and economic costs associated with alien-invasive species in the United States. Ecological Economics 52, $273-288$.

Rehner, S. A. \& Buckley, E. (2005). A Beauveria phylogeny inferred from nuclear ITS and EF1-a sequences: evidence for cryptic diversification and links to Cordyceps teleomorphs. Mycologia, 97, $84-98$.

Roy, H. E. \& Pell, J. K. (2000). Interactions between entomopathogenic fungi and other natural enemies; Implications for biological control. Biocontrol Science and Technology, 10, $737-752$.

Sparrow, M. K. (2000). The Regulatory Craft: Controlling Risks, Solving Problems and Managing Compliance. Washington DC USA: Brookings Press.

Tanada, Y. \& Kaya, H. K. (1993). Insect pathology. San Diego USA: Academic Press.

Thomas, M. B. \& Reid, A. M. (2007). Are exotic natural enemies an effective way of controlling invasive plants? Trends in Ecology and Evolution, doi:10.1016/j.tree.2007.03.003.

Thomas, M. B. \& Willis, A. J. (1998). Biocontrol - risky but necessary? Trends in Ecology and Evolution, 13, 325 - 329.

Torchin, M.E., Lafferty, K.D., Dobson, A.P., McKenzie, V.J. \& Kuris, A.M. (2003). Introduced species and their missing parasites. Nature, 421, 628 - 630 .

Van Lenteren, J. C. (2000). A greenhouse without pesticides: fact or fantasy? Crop Protection, 19, 375- 384.

Vestergaard, S., Cherry, A., Keller, S. \& Goettel, M. (2003). Safety of hyphomycete fungi as microbial control agents. In H. M. T. Hokkanen \& A. E. Hajek (Eds.), Environmental impacts of microbial insecticides. (pp. 35 - 62). Dordrecht The Netherlands: Kluwer Academic Publishers. 
Waage, J. K. (1997). Biopesticides at the crossroads: IPM products or chemical clones? In H. F. Evans (Chair), Microbial insecticides: novelty or necessity? (pp 11 - 20). British Crop Protection Council Symposium Proceedings No. 68, Farnham, UK.

Waage, J. K. (2001). Indirect ecological effects in biological control: the challenge and the opportunity. In E. Wajnberg, J. K. Scott \& P. C. Quimby (Eds.), Evaluating indirect ecological effects of biological control. (pp. 1-12). Wallingford: CABI Publishing.

Whipps, J. M. (2001). Microbial interactions and biocontrol in the rhizosphere. Journal of Experimental Botany, 52, $487-511$. 


\section{Box 1: Microbial control agents and biocontrol}

Micro-organisms form the most abundant and diverse group of living things on earth, and as such offer a vast resource for exploitation. Control agents of agricultural pests have been developed from microbial natural enemies in the bacteria, protozoa, fungi and viruses. These microbes are commonplace in nature, although it is likely that the majority of species are yet to be described. Of the known potential microbial control agents, only a very small fraction has been investigated for practical use. For example, while c. 750 species of entomopathogenic fungi are known, less than 20 have received serious attention as control agents of insect pests (Hawksworth et al., 1995; Copping, 2004). While many technical and ecological challenges remain to the exploitation of microbial control agents, they can form valuable components of ICM. Table 1 lists some representative species used as commercial control agents.

Table 1: Examples of microorganisms registered for use as control agents of agricultural pests

\begin{tabular}{|c|c|c|c|}
\hline Organism & Use & Pest & Target crops \\
\hline \multicolumn{4}{|l|}{ Bacteria } \\
\hline Agrobacterium radiobacter & Anti-bacterial agent & Crown gall (Agrobacterium tumefasciens) & soft fruit, nuts, vines \\
\hline $\begin{array}{l}\text { Xanthomas campestris } p v \text {. } \\
\text { poannua }\end{array}$ & Herbicide & Annual bluegrass & turf \\
\hline Bacillus subtilis & Fungicide & Fusarium, Pythium, Rhizoctonia spp. & $\begin{array}{l}\text { legumes, cereals, } \\
\text { cotton }\end{array}$ \\
\hline Bacillus thuringiensis & Insecticide & Various Lepidoptera, Diptera, Coleoptera & $\begin{array}{l}\text { vegetables, fruit, } \\
\text { cotton, rice, forestry }\end{array}$ \\
\hline \multicolumn{4}{|l|}{ Fungi } \\
\hline Lecanicillium longisporum & Insecticide & Aphids & $\begin{array}{l}\text { glasshouse edible \& } \\
\text { ornamental crops }\end{array}$ \\
\hline Phytophthora palmivora & Herbicide & strangler vine & citrus \\
\hline Trichoderma harzianum & Fungicide & Pythium, Phytophthora, Rhizoctonia & $\begin{array}{l}\text { orchards, ornamentals, } \\
\text { vegetables, glasshouse } \\
\text { crops }\end{array}$ \\
\hline \multicolumn{4}{|l|}{ Protozoa } \\
\hline Nosema locustae & Insecticide & grasshoppers, crickets & pasture \\
\hline Viruses & & & \\
\hline
\end{tabular}


Cydia pomonella granulosis

Insecticide

codling moth

apple, pear

virus

For more information see Copping (2004); Kabaluk \& Gazdik (2005). 